\title{
ALGUMAS CONSIDERAÇÕES SOBRE AS ORIGENS DA PREPARAÇÃo DE ÁCIDO NÍTRICO
}

\section{Maria Helena Roxo Beltran*}

Centro Simão Mathias de Estudos em História da Ciência - Pontifícia Universidade Católica de São Paulo - Rua Marquês de Paranaguá, 111 - Prédio I - sala 2 - 01303-050 - São Paulo - SP

Recebido em 2/7/97; aceito em 22/10/97

\begin{abstract}
SOME REMARKS CONCERNING THE ORIGINS OF PREPARATION OF NITRIC ACID. It is commonly acknowledged that the earliest recipe to prepare mineral acids dates from the XIIIth century, since it can be found in a text attributed to Geber. This paper intends to discuss this belief, taking into account recent studies on the Geberian corpus and also considering some ancient references to saltpeter.
\end{abstract}

Keywords: discovery of mineral acids; Geberian texts; Biringuccio's Pirotechnia.

\begin{abstract}
"Esse [licor], obtido mediante destilações artificiais, [...] tem uma propriedade aguda e o poder de corroer e transformar em si próprio, a prata ou qualquer outro metal nele colocado, à exceção do ouro. Não se parece com nada além de água pura. De fato trata-se de algo muito engenhoso motivo pelo qual devemos ser muito gratos ao filósofo, alquimista, ou seja lá quem tenha sido seu descobridor"1.
\end{abstract}

Tais palavras de admiração diante do material que hoje denominamos ácido nítrico foram escritas pelo mestre artesão metalurgista, nascido em Siena, Vanoccio Biringuccio (1480-c.1539), no seu De la Pirotechnia, publicado em 1540 em vernáculo. Essa obra, um dos mais afamados tratados técnicos renascentistas relacionados a mineração e metalurgia, compõem-se de dez livros. Oito desses livros tratam especialmente do trabalho com metais, desde as características de seus minérios até a fundição de peças, passando, evidentemente, por todo o processo de refinamento. O nono livro é dedicado a "vários trabalhos com fogo", envolvendo desde a alquimia e a destilação de "águas" até a cerâmica. O décimo livro versa "Sobre certos materiais combustíveis artificiais, e os procedimentos seguidos ao se prepararem fogos a serem utilizados em guerras e em festivais".

A organização dos livros e dos capítulos apresenta uma seqüência tal que, associada à clareza das descrições das técnicas expostas, permitiria ao leitor apreender os procedimentos envolvidos na metalurgia e nas diferentes artes abordadas na obra. Isso pode ser observado em sua descrição do procedimento de obtenção de "água forte" a partir de:

"[...] uma parte de salitre muito bem refinado e o triplo de alúmen de rocha também muito bem lavado. Se for possível, use um pouco daquela espécie vermelha do Levante ou Cartagena; ou então, use algum proveniente de La Tolfa; e se não, algum daquela espécie branca que tenha sido previamente colocada em um pote ou em outro recipiente sobre o fogo de modo a exalar toda a sua umidade. Misture junto com essas coisas uma oitava parte, ou menos, de areia, cascalho ou tijolo esmigalhado. Mas, me parece melhor usar resíduos de água forte mais uma vez, se os tiver. Quando tiver misturado essas coisas, [...] encha as cucúrbitas" 2 .

Essa mistura de salitre e alúmen devia destilada por horas até que "começasse a colorir os alambiques com fumos amarelos" A seguir aquecia-se vigorosamente por mais seis horas pois,

*Programa de Estudos Pós-Graduados em História da Ciência E-mail: 1beltran@exatas.pucsp.br
"Pela força desse fogo se fará com que todo espírito intrínseco e poderoso emane desses materiais. Isso estará terminado quando o alambique não estiver mais colorido com qualquer fumaça, e o alambique e o frasco coletor começarem a esfriar. Mesmo depois de obter todos esses sinais, mantenha o fogo por, no mínimo, uma hora ou mais"4.

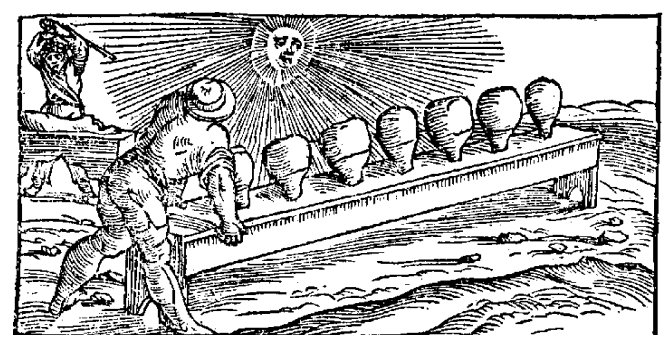

Preparação das cucúrbitas utilizadas na destilação de "água forte", Vannoccio Biringuccio, De la Pirotechnia, 1540.

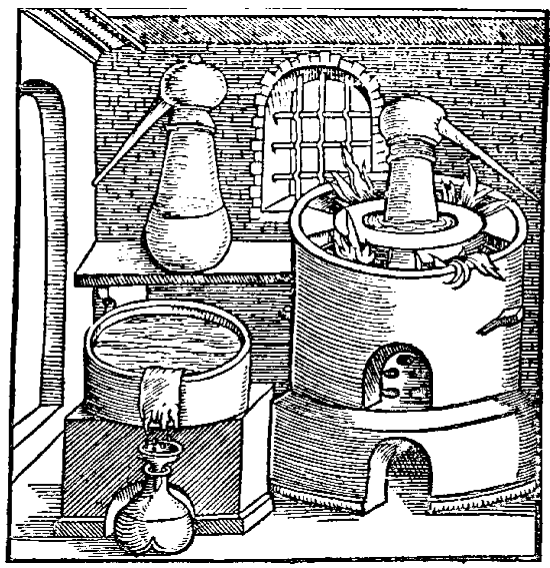

Destilação, Alchemiae Gebri Arabis ..., 1545.

Acrescente-se ainda que detalhadas descrições sobre construção do forno e a preparação dos vasos destilatórios precedem a descrição desse procedimento. Mas, transmitir claramente e mostrar as particularidades de seus conhecimentos especializados no trabalho com metais era mesmo a intenção de Biringuccio que, com isso, pretendia valorizar o seu ofício. Também era com esse mesmo intuito que procurava diferenciar a 
metalurgia da alquimia, criticando particularmente certo tipo de alquimistas que considerava fraudulentos. Ao mesmo tempo porém, reconhecia contribuição que os "filósofos ou alquimistas" deram à arte da metalurgia, como demonstra no primeiro trecho citado, entre outros.

Em seu livro, referências a obras anteriores relacionadas aos assuntos tratados são raras e bastante vagas, talvez, em parte, por falta de erudição, mas, também por priorizar os conhecimentos adquiridos e empregados na prática. Essa postura de Biringuccio poderia ser levada em conta para explicar sua falta de preocupação em identificar o descobridor da poderosa "água" que descreve no trecho citado. Entretanto, não parece ser o caso, pois a origem da produção dos ácidos minerais, tema bastante discutido pelos historiadores da química nas primeiras décadas do nosso século, merece, ainda hoje, ser retomado.

Tem sido tradicionalmente aceito por grande parte dos historiadores da química atribuir a primeira referência à produção de ácidos minerais ao legendário Geber, alquimista que teria vivido durante o século XIII. Tal idéia fundamentou-se num trecho presente em um dos opúsculos geberianos, o Liber de inventione veritatis, por vezes também chamado Liber de inventione perfectiones, em que se descreve a preparação de uma poderosa "água dissolutiva" a partir da destilação de vitríolo, alúmen e salitre. Essa receita, citada a seguir, consta do último capítulo do opúsculo (Capítulo XXIII), encontrado na quarta parte, dedicada a "remédios" empregados no tratamento de metais:

"Desejamos completar [este livro] com certas Águas e Óleos, muito necessários em Nosso Magistério. Com estes devemos concluir nosso Livro da Invenção da Perfeição. E primeiro começaremos com Nossa Água Dissolutiva a respeito da qual fizemos Menção em Nossa Summa da Perfeição, quando falamos da Dissolução com a Agudez das Águas.

Primeiro tome de Vitríolo de Chipre, lib. I. de Salitre, lib. ff. e de Alúmen Jamenoso ${ }^{5}$, uma quarta parte; extraia a Água com a Vermelhidão do Alambique (pois ela é muito Dissolutiva) e utilize-a nos Capítulos antes mencionados. Ela pode se tornar muito mais aguda, se nela se dissolver uma quarta parte de $\mathrm{Sal}$ amoníaco; pois isso dissolve Ouro, Enxofre e Prata"6.

Como pode ser verificado nesse trecho, tal receita é precedida de uma referência a "águas penetrantes" que teriam sido mencionadas na Summa perfectionis magisteri. Obra central do chamado corpus geberiano, a Summa foi um dos textos mais destacados na alquimia européia. Circulando em manuscritos desde pelo menos o final do século XIII, esse texto, juntamente com outros opúsculos geberianos, foi também amplamente difundido pela imprensa. A importância dessa obra, bem como a autoridade atribuída a Geber, identificado por muito tempo com o alquimista árabe Jabir ibn Hayyan, seria reconhecida e transmitida por diversos autores até pelo menos o século XVIII ${ }^{7}$.

As referências a "águas penetrantes" comparecem na Summa especialmente no item referente à dissolução. Se bem que nas edições consultadas ${ }^{8}$, esse trecho apresente variações na organização das orações e em alguns termos, a ordenação do conteúdo e o sentido dos textos são os mesmos. Inicialmente, o autor define dissolução como "a transformação de um material seco em água" e, logo a seguir, estabelece:

"Dizemos, portanto, que a perfeição de toda dissolução é alcançada com águas penetrantes, especialmente aquelas agudas, acres e pungentes 9 que não tenham sedimentos. São dessa sorte vinagre destilado, uvas verdes, ameixas amargosas, peras muito acres, romãs, e outras coisas como estas também destiladas" 10 .

Cabe notar que, apesar do autor se referir à destilação, essas "águas" eram, provavelmente, preparadas pela simples filtração do suco extraído das frutas, o que permitiria livrá-las dos sedimentos. De fato, um tipo de destilação realizada "sem fogo", descrito por Geber em outra parte da Summa, consiste exatamente em filtrar a "água", procedimento que era conhecido como destillatio per filtrum. Assim, considerando a ênfase que o autor coloca na ausência de sedimentos que essas águas deveriam ter, e levando em conta que a destilação por filtro garantiria essa purificação da "água", a filtração deveria mesmo ser o procedimento empregado.

O texto sobre a dissolução prossegue apresentando a "causa dessa invenção", ou seja, da dissolução, que seria "tornar sutis aqueles materiais que não apresentam fusão ou penetração". Por fim, são apresentados dois métodos de se realizar a dissolução, os quais diferem apenas quanto à fonte de aquecimento empregada - imersão em estrume, e banho-maria - mas, em ambos, o processo é iniciado acrescentando-se vinagre destilado ao material que previamente se calcinava.

Assim, "as águas penetrantes" indicadas por Geber na Summa perfectionis seriam materiais ácidos, tais como vinagre e sucos de origem vegetal, "destilados por filtro", não se notando aqui menções a ácidos minerais ou a procedimentos semelhantes ao apresentado no Liber de inventione veritatis.

Os estudos sobre Geber e os textos a ele atribuídos, bem como as idéias sobre sua identificação, ou não, com Jabir ibn Hayyan desencadearam, a partir do final do século passado, debates que abrangem desde a identidade desse autor, conduzindo a amplas discussões sobre a data em que esses textos teriam sido escritos ${ }^{11}$. Embora esse complexo debate não pareça ainda completamente superado, muitos dos estudos desenvolvidos nesse processo reforçaram a idéia da existência de um Geber latino ou, pelo menos, de uma escola geberiana responsável pela elaboração do conjunto de textos que constituem o chamado corpus geberiano.

Entretanto, estudos recentes vieram a confirmar uma suposição proposta por M. Berthelot no final do século passado, revelando que, embora a Summa perfectionis tenha sido escrita ao final do século XIII, os outros opúsculos, entre eles o $D e$ inventione veritatis, onde se encontra a supracitada receita para preparação de ácidos minerais, seriam obras pseudoepigráficas produzidas em épocas posteriores. De fato, não se conhecem manuscritos desses opúsculos com datas anteriores ao início do século $\mathrm{XV}^{12}$.

Com isso em vista, pode-se considerar a possibilidade de que a inclusão da receita que conduz claramente à obtenção de ácidos minerais presente no Liber de inventione veritatis constituísse mesmo um complemento às "águas dissolutivas" de origem vegetal mencionadas na Summa, provavelmente com a intenção de "atualizar" esse texto, uma vez que, no início do século XV, receitas para preparação de ácidos minerais já circulavam em outros manuscritos ${ }^{13}$.

As idéias tão generalizadas de se atribuir a descoberta dos ácidos minerais a Geber, considerado também como o primeiro alquimista a mencionar o salitre ${ }^{14}$, e de datá-la no século XIII, ficam ainda mais abaladas quando se leva em conta que referências a esse último material podem ser encontradas em textos elaborados em datas muito anteriores. Assim, por exemplo, o estudioso Sherwood Taylor refere-se a uma primeira menção ao salitre, sob o nome de "neve chinesa", presente num texto árabe de 1248, mas sugerindo uma provável origem dos conhecimentos sobre esse material no oriente distante ${ }^{15}$. Tal texto seria assim contemporâneo à cópia realizada no século XIII do Liber ignum ad comburendos hostes, atribuído a Marcus Graecus, e tido como o primeiro a mencionar claramente a utilização do sal petrosum em procedimento para confeccionar "fogos volantes"16. Outros autores consideram viável que o salitre fosse o ingrediente secreto do famoso "fogo grego", uma poderosa mistura combustível que entrava em ignição em contato com a água, e que teria sido utilizada pelos bizantinos já durante o século VII ${ }^{17}$. Há ainda outras indicações sugerindo o conhecimento do salitre por culturas orientais em datas muito mais remotas. Vestígios sobre o uso de salitre como medicamento adstringente, foram encontradas num tablete sumério do 
final do terceiro milênio antes de Cristo ${ }^{18}$. Além disso, esse material supostamente compareceria também em receitas assírias relativas à confecção de vidros, datando do século XVII a.C. ${ }^{19}$. Mas, uma indicação mais forte sobre o conhecimento do salitre foi encontrada num texto chinês cujas origens remontariam ao século II, e que seria a partir de então retrabalhado e ampliado, principalmente durante o início do século VI. O texto, que traz o título "Trinta e seis métodos de transformar sólidos em solução aquosa", descreve procedimentos, muitos dos quais envolvendo a utilização de vinagre e salitre, mistura que poderia agir sobre diferentes materiais sólidos submetidos a demorados processos de dissolução, de modo análogo a uma solução de ácido nítrico ${ }^{20}$.

Tais menções sugerem a possibilidade de que a produção de ácido nítrico possa ter suas raízes em períodos muito antigos; tal conhecimento, entretanto, teria sido mantido em segredo por muito tempo. De fato, levando-se em conta que as técnicas metalúrgicas desde tempos remotos foram cercadas por extremado sigilo ${ }^{21}$, é possível supor o quão zelosamente uma possível receita para preparação da poderosa "água forte" devia ser guardada entre os grupos de metalurgistas que detivessem esse conhecimento. Além disso, como a operacionalização dessa receita tinha condições para ser verificada no mínimo a partir do século XIII, quando a técnica de destilação e todos os materiais necessários, inclusive o salitre, eram com certeza conhecidos na Europa, é de se considerar que desde essa época, senão antes, a produção de "água forte" tenha sido mantida em segredo.

Textos trazendo receitas claras sobre a produção de ácidos minerais só se encontram mais freqüentemente em livretos impressos a partir do século $\mathrm{XVI}^{22}$. Mas, antes de sua ampla divulgação pela imprensa, essas receitas passariam a ser ocasionalmente registradas em manuscritos desde pelo menos o século $\mathrm{XIV}^{23}$. Então, por volta do início do século XV, uma receita para obtenção de ácidos foi incorporada ao corpus geberiano, apresentando-se em manuscritos do Liber de inventione veritatis.

Assim, ao se pensar sobre a história da produção de ácidos minerais, deve-se, por um lado, relativizar a importância tradicionalmente atribuída aos textos geberianos e ao século XIII como referenciais. Mas, por outro lado, não se pode desconsiderar a possibilidade de que a preparação de ácidos minerais tenha origens muito mais antigas. Os indícios aqui levantados sugerem caminhos que podem conduzir a raízes muito remotas desse conhecimento, já encobertas na época em que Biringuccio o divulgava e expressava sua admiração pela engenhosa "água forte", agradecendo ao seu desconhecido descobridor.

\section{AGRADECIMENTOS}

Este estudo faz parte de nossa pesquisa de pós-doutoramento em realização com o apoio da FAPESP.

\section{REFERÊNCIA}

1. V. Biringuccio. The Pirotechnia of Vannoccio Biringuccio: The Classic Sixteenth-Century Treatise on Metals and Metllurgy, trad. ingl., introdução e notas por Cyril Stanley Smith e Martha Teach Gnudi, reimp.; N. York, Dover 1990, p. 181.

2. Ibid., p. 185.

3. Ibid., p. 186.

4. Ibid., p. 186.

5. Optou-se por essa tradução já que no texto em inglês, o termo usado é Jamenous Allom, certamente numa referência ao "alúmen do Yemen" freqüentemente mencionado em textos relacionados à e as práticas.

6. Geber, The Works of Geber, trad. ingl. por Richard Russel
(1678), organizado por E. J. Holmyard; Londres/Toronto/ N. York; J. M. Dent \& Sons Ltd./ E. P. Dutton; \& Co. Inc. 1928, pp. 223-224.

7. Allen G. Debus. "The 'Geber's Tradition in Western Alchemy and Chemistry", Journal of the History of Arabic Science, 8; pp. 3-29, impresso em 1988, p. 5.

8. Utilizaram-se neste estudo as duas seguintes edições da Summa: The Summa Perfectionis of Pseudo-Geber, edição crítica, tradução e estudo realizados por William Newman, Leiden/ N. York/ Kobenhavn/ Köln, E. J. Brill; 1991, daqui para adiante indicada como "Geber, Summa" e a edição organizada por E. J. Holmyard; já citada na nota 6, daqui para adiante indicada como "Geber, Works." $\mathrm{O}$ trecho referente à dissolução encontra-se em Geber, Summa, pp. 708-710, correspondendo ao item 48 do "Livro II, Sobre os Princípios deste Magistério e de sua Perfeição", que traz a rubrica "Discurso sobre a dissolução"; e em Geber, Works, pp. 107-109, correspondendo ao capítulo XV, intitulado "Sobre a dissolução e sua causa", Parte IV, primeiro livro.

9. Em Geber, Works, é ainda acrescentado o adjetivo "salinas" para qualificar essas "águas".

10. Geber, Summa, pp. 708-9 (trad. ingl.), pp. 430-431 (texto em latim); Geber, Works, pp. 107-8. Para esta nossa tradução, procurou-se manter os adjetivos o mais próximo possível dos termos empregados no texto em latim.

11. Tal debate, que posteriormente passou a ser denominado como a questão Jabir-Geber, teve início há cerca de um século como os estudos sobre a Summa perfectionis magisteri que foi inicialmente considerada como uma tradução latina de um texto escrito pelo árabe Jabir ibn Hayyan, que teria vivido no século VIII. Entretanto, estudos posteriores viriam a indicar que esse texto tivesse sido por um alquimista latino, Geber, que teria vivido durante o século XIII. Mais recentemente foi proposto que a autoria da Summa fosse de um monge, Paulo de Taranto, sobre o qual também pouco se sabe. Históricos sobre esse debate podem ser encontrados em Da Alquimia à Quími$c a$, São Paulo, Nova Stella/EDUSP, 1989, de Ana Maria Alfonso-Goldfarb, pp. 140-143, e no estudo de W. Newman, em Geber, Summa, pp. 57-63.

12. W. Newman, op. cit., pp. 72-82.

13. As principais referências citadas a esse respeito presentes na bibliografia secundária podem ser encontradas, por exemplo, em R. Multhauf, The Origins of Chemistry, N. York; F. Watts Inc.; 1967 p. 207, onde esse estudioso apresenta receitas de ácidos minerais presentes em edições impressas das obras de autores que acreditava serem contemporâneos de Geber, tais como Vitalis de Furno (morto em 1327), Pro conservada sanitate, e Petrus Hispanus (1215-1277) Thesaurus pauperum; R. Forbes em seu A Short History of the Art of Distillation, reimp.; Leiden, E. J. Brill; 1970, pp. 63-64, refere-se apenas à primeira dessas receitas; ainda outra receita, encontrada em manuscrito do início do século XIV (MS. Bologna 139(105), é citada por Newman, op. cit., p. 106, nota 38.

14. R. Multhauf, op. cit., p. 172.

15. F. Sherwood Taylor, A History of Industrial Chemistry, N. York, Abelard-Shuman, p. 108.

16. Marcellin Berthelot, Histoire des Sciences, Paris Imprimiere Nationale, 1893, vol. I, pp. 89-135; é interessante notar que Biringuccio, op. cit., pp. 436-439, descreve algumas misturas incendiárias que datariam "do tempo de Alexandre o Grande", sobre as quais diz que foram escritas por Marcus Graecus "talvez o maior inventor ou um grande experimentador e praticante de tais coisas".

17. Vide, por exemplo, N. D. Cheronis, "Chemical warfare in the Middle Ages. Kallinikos"prepared fire", Journal of Chemical Education, ago/1937:360-365. 
18. Samuel Noah Kramer, History Begins at Sumer, University of Pensylvania Press 1981, pp. 60-64.

19. R. Campbell Thompson, A Dictionary of Assyrian Chemistry and Geology, Oxford, Clarendon Press, 1936, pp. xxi-xxvii, e Apêndice II.

20. J. Needham, Ts'ao T'ien-Ch'in, Ho Ping-Yü. “An Early Medieval Chinese Alchemical Text on Aqueous Solutions", Ambix, 7(3): 122-158, 1959.

21. O caráter secreto e sagrado do trabalho do artesão, especialmente do que lidava com metais, foi estudado em profundidade por Mircea Eliade em seu Ferreiros e Alquimistas, Lisboa, Relógio d'água, 1987.

22. Sobre esses livretos, veja de William Eamon, Science and the Secretas of Nature: Books of Secrets in Medieval and Early Modern Culture, Princeton, Princeton, University Press 1996, pp. 119-126; sobre as edições dos livretos de metalurgia vide A. Sisco, "How Old is the Bergbüchlein?", Isis, 43: 337-343, 1952, e H. C. Hoover \& L. H. Hoover; "Appendix B.; Ancient Authors",em Georgius Agricola, De re metallica, trad. ingl. da ed. de 1556, notas e comentários de H. C. Hoover \& L. H. Hoover; NovaYork, Dover 1950, pp. 607-615.

23. A realização de levantamento inicial de manuscritos contendo essas receitas constitui uma parte de nosso projeto de pesquisa, ora em desenvolvimento. 